\title{
Da escola para a vida: a importância do letramento escolar
}

\author{
Maria Cecília de Magalhães Mollica \\ Marisa Beatriz Bezerra Leal
}

\begin{abstract}
RESUMO
O estudo tem por objetivo verificar como os conhecimentos adquiridos na escola são aproveitados por alunos adultos num Programa de Alfabetização da Universidade Federal do Rio de Janeiro. Testes com um grupo de alunos do Programa demonstraram que existe maior dificuldade na linguagem do que na matemática. Provou-se também que os aprendizes lançam mão da experiência de mundo para resolver questões do letramento escolar.
\end{abstract}

Palavras-chave: letramento escolar, letramento social, transferência.

\section{Título em inglês: FROM SCHOOL TO LIFE: THE IMPORTANCE OF SCHOLAR LITERACY}

Index Terms: literacy of school, social literacy, transference.

\section{Introdução}

Este artigo levanta algumas questões referentes à pesquisa ${ }^{1}$ que estamos desenvolvendo no âmbito do Programa de Alfabetização da UFRJ para Jovens e Adultos. O estudo contempla a articulação dos conhecimentos de matemática e de língua portuguesa nos termos de Mollica e Leal (2006a), para investigar o diálogo entre letramento social e letramento escolar, de forma a obter subsídios para melhor adequar metodologias destinadas a pessoas de pouca ou nenhuma escolarização. Buscamos conferir, comparativamente, o grau de aproveitamento do letramento escolar por parte dos alunos e

\footnotetext{
${ }^{1}$ Os auxiliares de pesquisa que participam deste estudo são os bolsistas de Iniciação Científica: Fábio Galvão do IM, bolsa PR5/UFRJ, e Karine Bastos do Departamento de Lingüística, PIBIC/UFRJ.
} 
a capacidade de transferência dos saberes escolares para as situações de vida real, examinando o desempenho de questões de português e de matemática.

Os cidadãos não alfabetizados na idade jovem e adulta, inseridos numa cultura letrada, encontram-se diante da necessidade de construir hipóteses a respeito da linguagem escrita e da escrita matemática, embora já possuam linguagem e cálculo mental adquiridos através de estratégias inatas ou intuitivas. O cotidiano exige que o indivíduo crie táticas para enfrentar situações, como administrar questões referentes a salário, efetuar pagamentos, reconhecer e selecionar produtos, relacionando-os aos seus respectivos valores, pagar bilhetes de transporte, distinguindo-os conforme o veículo de locomoção, destino, assim como adquirir sentido de orientação em locais públicos, através de sinais, placas, mapas e similares. Desse modo, é relevante verificar o grau de letramento dos alfabetizandos do Programa, tendo em vista os conhecimentos adquiridos fora e dentro da escola. A perspectiva do estudo não se acha restrita à capacidade de decifrar códigos, mas às diferentes práticas de letramento (cf. SOARES, 2003), que podem estar direta ou indiretamente associadas a situações de uso da leitura, da escrita e da escrita matemática.

Em um primeiro momento, para investigar o grau de letramento social em alunos em processo de alfabetização, o estudo voltou-se para a análise acerca de portadores, baseada no trabalho de Moreira (1992). A partir de entrevistas realizadas com alunos do Programa, escolhidos aleatoriamente, pôde-se constar como os jovens e adultos com baixo grau de instrução identificam os suportes textuais e lhes conferem funções. Nossa intenção consistiu em aquilatar a capacidade de inserção dos indivíduos testados em atividades do cotidiano que envolvem conhecimentos matemáticos, de leitura e de escrita, uma vez que a utilização de suportes textuais reflete saberes de mundo que o aluno possui, mesmo que não domine noções específicas afetas ao letramento escolar, relacionadas a diferentes tipos de texto e gêneros discursivos, bem como à função das letras e dos números. Esse experimento demonstrou indícios importantes da influência do letramento social sobre o escolar, o que nos leva a crer que os indivíduos se apropriam de saberes presentes na cultura letrada independentemente do processo escolar sistemático. Em contrapartida, pouco se sabe quanto à influência do aprendizado escolar no contexto social.

Concluída a primeira fase, então, voltamo-nos para examinar os modos como os alunos percorrem o caminho inverso: a transferência e a aplicação de conhecimento do espaço escolar para o social nas situações do dia-a-dia. Desejamos, assim, conferir se os alfabetizandos conseguem transportar a aprendizagem verificada em sala-de-aula e, dessa 
forma, refletir sobre os critérios de mensuração de graus de aproveitamento do letramento escolar.

Para fins de coleta de dados, utilizamos a aplicação em sala-de-aula do PRIMEIRO CADERNO (cf. MOLLICA; LEAL, 2006b), cujas propostas pedagógicas partem de situações concretas vividas fora da escola, com características típicas de letramento social, de acordo com os princípios de Paulo Freire e dos PCNs Português e Matemática. Os primeiros resultados divulgados neste artigo demonstram, surpreendentemente, maior desenvoltura dos alunos na escrita matemática em comparação à escrita em português.

\section{Experimento no espaço escolar: perfil da amostra e instrumento de testagem}

O experimento pretendeu examinar: (a) o desempenho que os alfabetizandos apresentam quanto às questões de ordem ortográfica e gramatical; (b) algumas noções de escrita matemática. Contamos com um universo de 25 indivíduos do Programa de Alfabetização da UFRJ para Jovens e Adultos, cujo perfil considera as variáveis "gênero", "faixa etária", "tempo de escolarização" e "inserção no mercado de trabalho". Os quadros que se seguem demonstram a distribuição da amostra pesquisada.

\begin{tabular}{|l|l|}
\hline Homens & $24 \%$ \\
\hline Mulheres & $76 \%$ \\
\hline
\end{tabular}

Quadro 1. Distribuição dos 25 indivíduos por gênero em percentuais.

\begin{tabular}{|l|c|}
\hline de 15 a 24 anos & $12 \%$ \\
\hline de 25 a 34 anos & $24 \%$ \\
\hline de 35 a 44 anos & $24 \%$ \\
\hline de 45 a 54 anos & $20 \%$ \\
\hline de 55 a 64 anos & $8 \%$ \\
\hline de 65 anos ou mais & $12 \%$ \\
\hline
\end{tabular}

Quadro 2. Distribuição dos 25 indivíduos por faixa etária em percentuais.

\begin{tabular}{|l|l|}
\hline Nunca freqüentou escola formal & $16 \%$ \\
\hline Freqüentou escola formal por menos de 4 anos & $68 \%$ \\
\hline Freqüentou escola formal por mais de 4 anos & $16 \%$ \\
\hline
\end{tabular}

Quadro 3. Distribuição percentual dos 25 indivíduos por tempo de escolarização em percentuais. 


\begin{tabular}{|l|l|}
\hline Trabalham & $36 \%$ \\
\hline Não trabalham & $64 \%$ \\
\hline
\end{tabular}

Quadro 4. Situação funcional dos 25 indivíduos em percentuais.

De acordo com os quantitativos dos quadros de 1 a 4, os indivíduos testados são majoritariamente do sexo feminino, acham-se na faixa de 25 a 54 anos, já freqüentaram escola e não trabalham. Dentre muitas conclusões, podemos inferir que a amostra contém um reduzido percentual de alunos com pouco ou nenhum contato com noções veiculadas na escola.

Presume-se que a experiência de mundo facilite as práticas escolares, do mesmo modo que os saberes aprendidos na escola tornem os cidadãos mais preparados às exigências do mundo letrado. Assim, aprender a operar a concordância nominal e verbal, por exemplo, de acordo com os ditames da tradição gramatical, ou reconhecer as unidades de medida e monetária e operá-las em conformidade com as convenções dos algoritmos matemáticos, representa equipar o cidadão tecnicamente, de modo a tornar seu conhecimento tanto mais específico quanto mais amplo, para adequá-lo às diferentes necessidades lógico-lingüísticas que se lhes apresentam no cotidiano.

Tome-se o exemplo da proposta pedagógica do referido Manual de Exercícios.

\section{Exemplo de questão incluída no teste:}

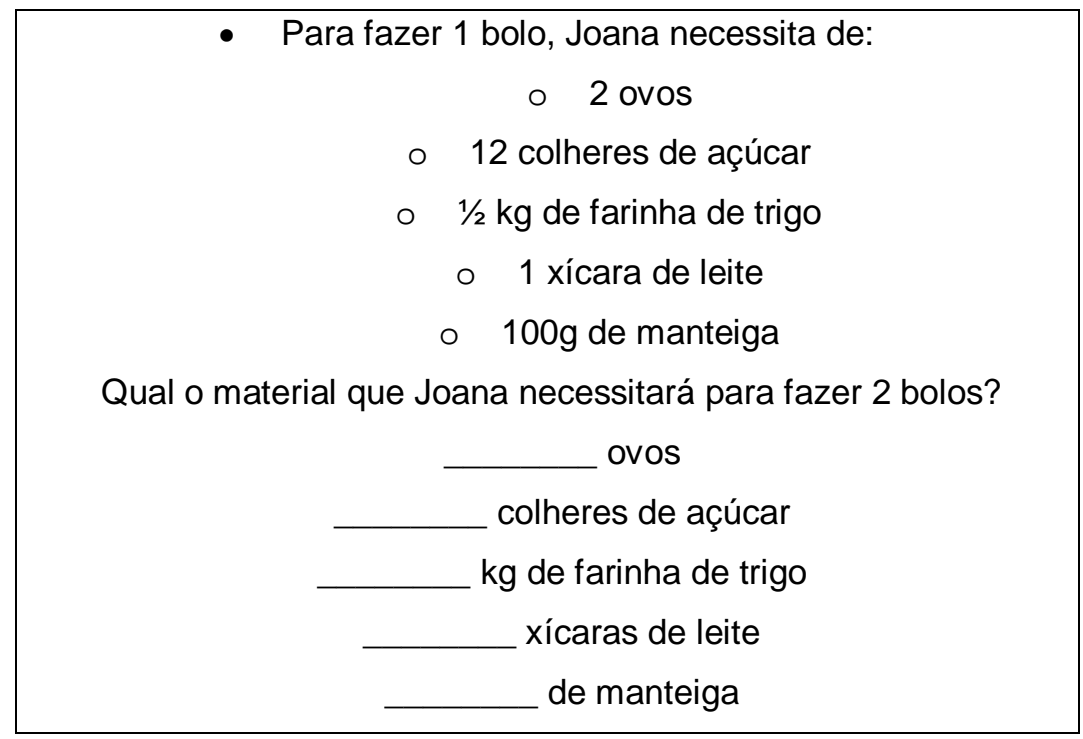


O texto acima é uma receita de bolo, constituído de um gênero textual com características próprias. No caso em exame, temos a explorar as noções de plural, em português, e de dobro, em matemática. A questão relevante prende-se ao fato de que a pluralidade é marcada por morfemas específicos da estrutura da língua e o conceito de dobro é definido como duas vezes o valor de um número dado.

Tais noções contextualizadas numa situação real de vida, de conhecimento comum aos alunos, têm que ser, digamos, abstratizadas na escola, de modo que os alfabetizandos as apliquem em diferentes situações de mundo, lançando mão, respectivamente, das operações de pluralização, de adição e multiplicação. O trabalho do alfabetizador consiste então em preencher as lacunas com a turma, conscientizar os alunos quanto às formas de marcar a concordância e, finalmente, efetuar a operação de multiplicação solicitada.

Exemplos assim compõem o teste, como se verifica a seguir, aplicado nos alunos do Programa de Alfabetização da UFRJ para Jovens e Adultos, em maio de 2006.

\section{UNIVERSIDADE FEDERAL DO RIO DE JANEIRO Programa de Alfabetização da UFRJ para Jovens e Adultos Pesquisa: Letramento Escolar e Social}

Nome:

Data:

Alfabetizador(a):

1) Observando o calendário abaixo, responda:

\begin{tabular}{|c|c|c|c|c|c|c|c|}
\hline \multicolumn{5}{|c|}{ Maio 2006 } & \multicolumn{1}{|c|}{} \\
\hline D & S & T & Q & Q & S & S \\
\hline & 1 & 2 & 3 & 4 & 5 & 6 \\
\hline 7 & 8 & 9 & 10 & 11 & 12 & 13 \\
\hline 14 & 15 & 16 & 17 & 18 & $\underline{19}$ & 20 \\
\hline$\underline{21}$ & 22 & 23 & 24 & 25 & $\underline{26}$ & 27 \\
\hline 28 & 29 & 30 & 31 & & & \\
\hline \hline
\end{tabular}

- Qual é o mês apresentado pelo calendário?

- Qual é o ano apresentado? 
- Quantos dias existem em uma semana?

- Quantos dias existem em uma quinzena?

- Quantos meses existem em um ano?

2) Complete, conforme o exemplo:

$\mathrm{Um}$ ano $\rightarrow$ Dois anos

Um dia $\rightarrow$ Três

Uma semana $\rightarrow$ Quatro

3) Determine:

- O dobro de 4 copos são copos.

- A metade de $500 \mathrm{~g}$ é igual a g.

- A metade de 14 dias é igual a dias.

- O triplo de $R \$ 100,00$ é igual a $R \$$

4) Responda:

- Se João tem 25 anos e seu pai tem 2 anos a mais que o dobro de sua idade. Quantos anos tem o pai de João?

- Sabendo que uma dúzia de laranjas custa $R \$ 1,00$, quanto custa duas dúzias e meia?

- Atualmente, uma passagem de ônibus custa $\mathrm{R} \$ 1,90$. Se tivesse que pagar duas passagens, quanto gastaria?

5) Efetue:

$17 \times 2=$

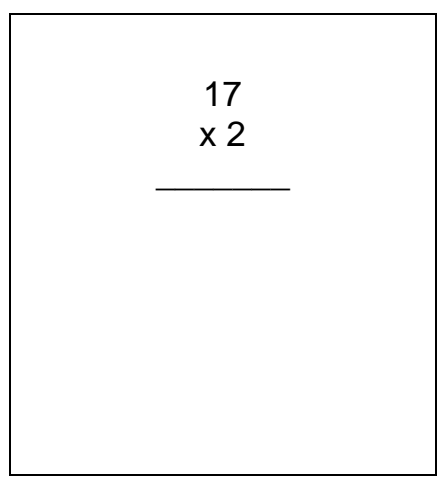

$18+13=$

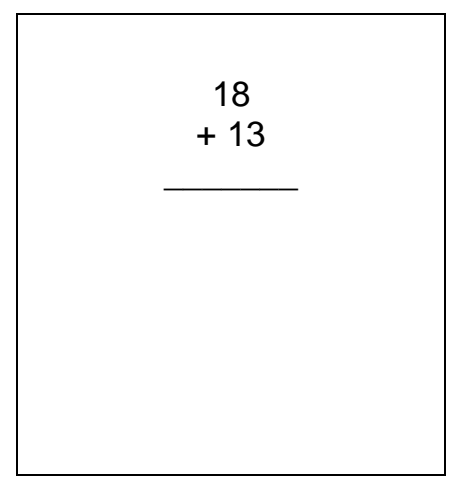

$30-16=$

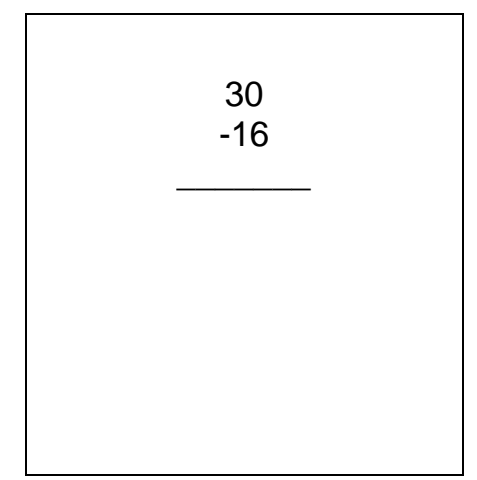

6) A Terra faz parte do Sistema Solar, que é formado pelo Sol, por vários satélites e nove planetas.

Os planetas são: Mercúrio, Vênus, Terra, Marte, Júpiter, Saturno, Urano, Netuno e Plutão. O maior planeta do Sistema Solar é Júpiter e o menor planeta do Sistema Solar é Plutão. 


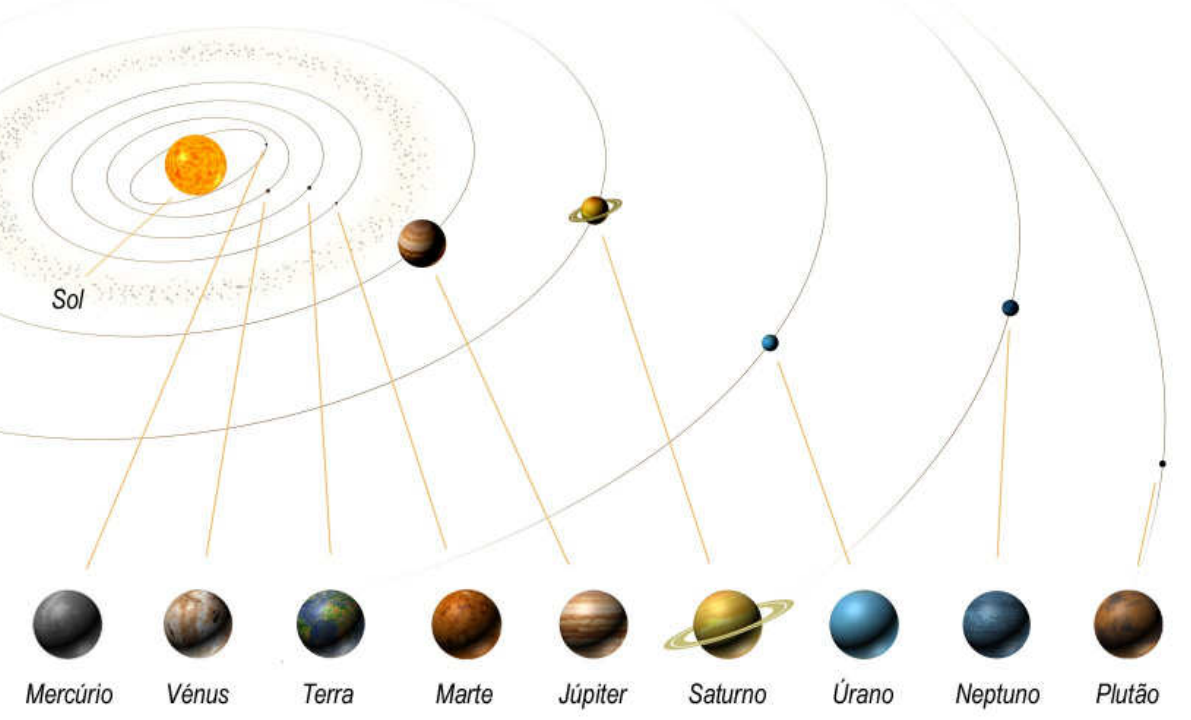

- Passe para o singular:

a) As estrelas

b) Os astros

c) Dois planetas

- Passe para o plural:

a) O satélite

b) A estrela

- Passe para o feminino:

a) Um menino

b) O professor chegou.

- Passe para o masculino:

a) A professora

b) A garota caiu. 
c) A médica não estava no hospital.

Como se pode observar, o instrumento de avaliação abarca conceito de gênero (masculino e feminino) e de número (singular e plural), noções da linguagem matemática (dobro, metade e triplo), tendo como meta verificar o domínio do registro das regras.

\section{Primeiros resultados}

Seguem os resultados gerais do teste inicialmente aplicado:

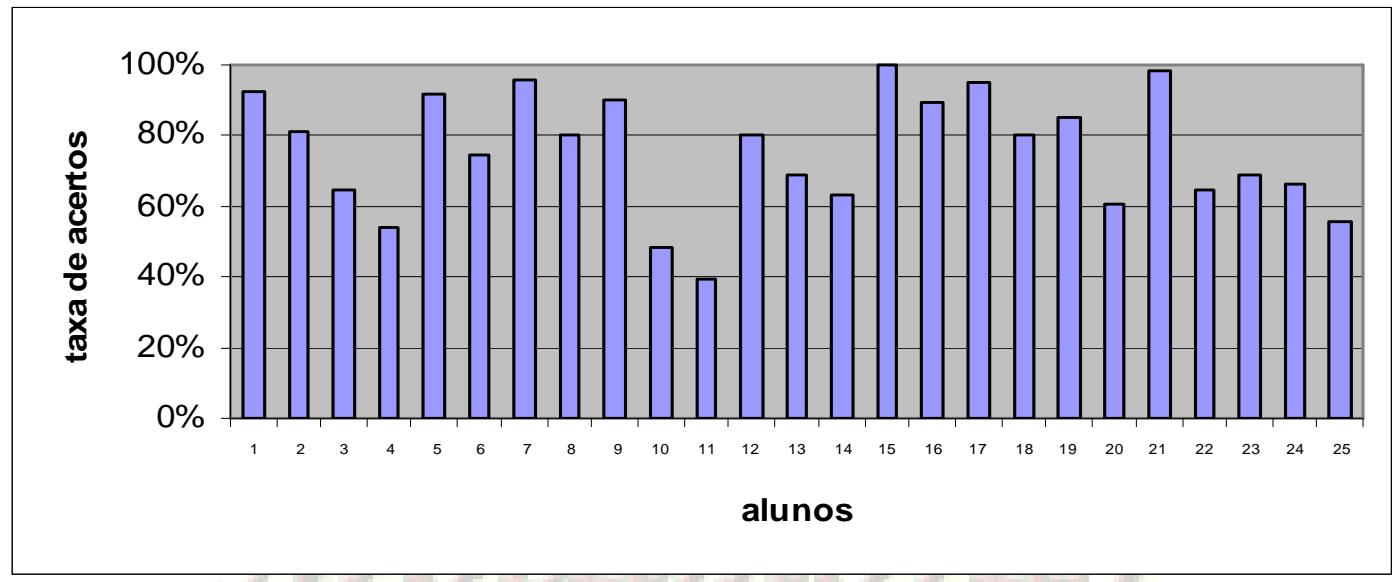

Gráfico 1. Taxa de acerto por aluno

Pelo gráfico 1, observa-se que apenas 1 indivíduo adulto de 27 anos, tendo estado no ensino formal por 5 anos, apresentou taxa de acerto de 100\%. Mais da metade (52\%) dos indivíduos obteve um percentual de acerto igual ou superior a $75 \%$ e apenas 3 indivíduos não alcançaram nem 50\% de acerto. Os piores resultados são provenientes dos menos escolarizados.

Analisando os resultados referentes às duas disciplinas, separadamente, chegamos à seguinte distribuição: 


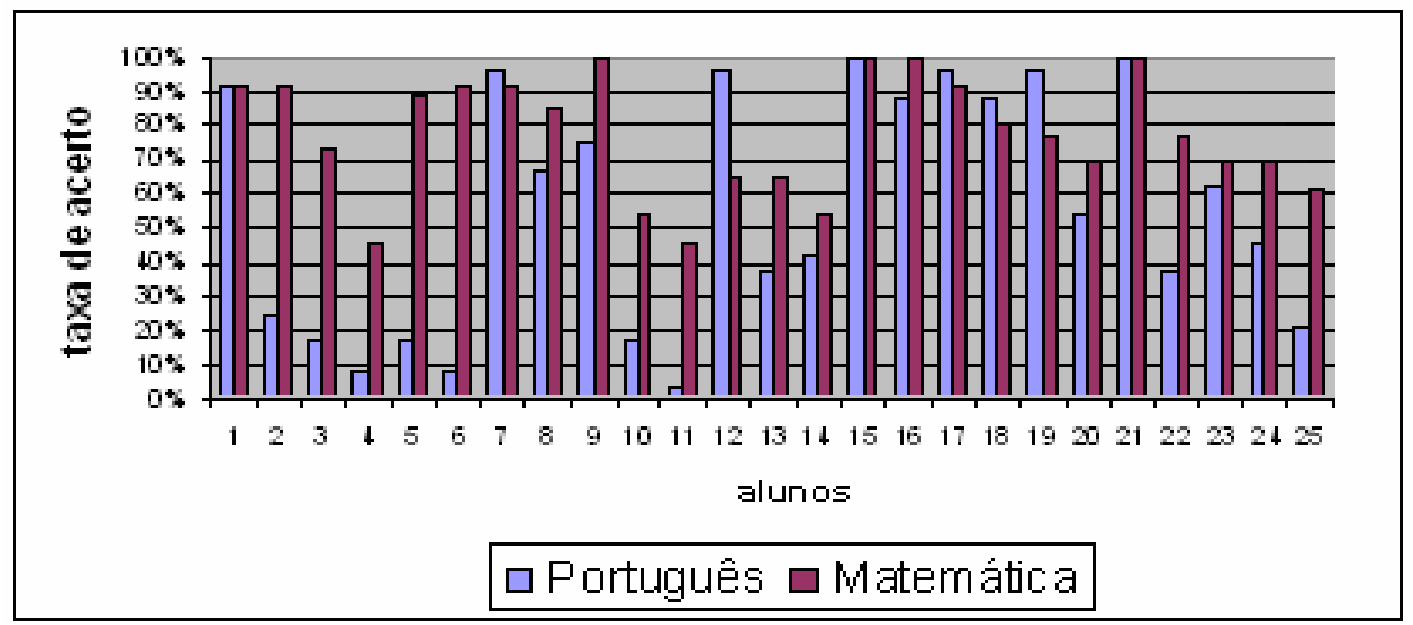

Gráfico 2. Taxa de acerto em português e em matemática por aluno

O gráfico 2 mostra indícios de melhor desempenho em matemática em comparação a português. Note-se que, em português, quase todas as questões do teste envolveram a migração da fala na escrita, o que nos levar a supor que a pressão da oralidade na escrita é muito forte (cf. MOLLICA, 2004).

Para melhor ilustrar algumas dificuldades observadas, tanto nas questões que envolvem conceitos da língua materna, quanto nas que envolvem habilidades matemáticas, como resultado da análise dos testes, vale a pena destacar: os alunos apresentaram desvios ortográficos como: "ceti" (sete), "sente" (sete), "quize" (quinze), "douze" (doze), "meize" (meses) e "naio" (maio). Ainda no âmbito da ortografia, foram encontrados casos, em que, no lugar de "estrela", estava escrito "estreia". Esse equívoco explica-se pela dificuldade de distinção entre o "L" minúsculo e o "I" maiúsculo pelos alfabetizandos da amostra.

Os resultados mostram ainda que as maiores dificuldades foram encontradas nas questões 2 e 6, justamente as que exigem habilidades de apropriação das variantes de prestígio em língua materna, como a concordância nominal, regra variável cuja variante padrão os alunos do Programa não dominam. Foi possível reparar determinados desvios de concordância como: "dois planeta”, “os astro", “a estrelas", “o satélites”, "um menina”, "a professor", "um médica”, “a professor", "professoro" (presença da desinência -o para marcar o masculino). Na mesma questão, $23 \%$ dos alunos responderam "doi" como singular de "dois".

Evidencia-se também que, dentre as questões de matemática, as que mais apresentam indicadores de letramento social são as que garantem melhor desempenho dos alunos. Dentre as questões que permitem calcular mentalmente, $88 \%$ dos avaliados as fizeram e apenas $12 \%$ registraram as operações envolvidas para chegar ao resultado. Vale 
ressaltar, entretanto, que a estratégia do cálculo mental não foi garantia de acerto. Nem todos os que utilizaram algum tipo de registro também obtiveram êxito total. Com base nos exemplos de registro das operações matemáticas, percebe-se que muitos alfabetizandos, a fim de chegar ao resultado de dobro, optaram pela adição no lugar da multiplicação.

- O dobro de 4 copos: $4+4=8$

- Atualmente, uma passagem de ônibus custa $\mathrm{R} \$ 1,90$. Se tivesse que pagar duas passagens, quanto gastaria? $R \$ 1,90+R \$ 1,90=R \$ 3,80$

Quanto às operações matemáticas, notou-se que $80 \%$ as reconheceram, ou seja, souberam diferenciar a adição, a subtração, a multiplicação e a divisão. Em contrapartida, é possível verificar alguns equívocos realizados por $20 \%$ dos jovens e adultos. No registro $17 x 2=19$, conclui-se que o símbolo da multiplicação (x) foi confundido com o da adição (+). De qualquer forma, quem supôs a adição, por mais que não tenha percebido a distinção, acertou o cálculo. Alguns alunos apresentam também dificuldade em trabalhar com casas decimais. Na maioria das vezes, acertavam o cálculo matemático, mas confundiram-se quanto à colocação da vírgula. Os resultados revelam que $56 \%$ dos alunos testados foram capazes de trabalhar com as casas decimais, embora $44 \%$ tenham encontrado dificuldades.

- A metade de $500 \mathrm{~g}$ é: $2500 \mathrm{~g} / 25 \mathrm{~g}$

- Sabendo que uma dúzia de laranjas custa $\mathrm{R} \$ 1,00$, quanto custa duas dúzias e meia? $R \$ 2,0,50 / R \$ 25,00$

\section{Considerações finais}

Uma discussão relevante para o prosseguimento da pesquisa diz respeito ao grau de inserção das propostas pedagógicas no mundo do aluno. Uma hipótese forte é a de que, quanto mais referências da vida real os exercícios apresentem, tanto mais provável se verifica o desempenho escolar. Pode-se supor, então, que os alunos atinjam melhor performance nas questões em que o letramento social está inserido mais fortemente no letramento escolar, de acordo com as recomendações dos PCNs. Tal fato sugere que a prática social da leitura e da escrita, bem como o exercício diário de cálculo mental, sendo habituais na realidade dos jovens e adultos do Programa, tornam-se vetores propulsores no processo de letramento escolar: os registros das operações, por estarem mais associados ao ambiente escolar, prestam-se a grau maior de dificuldade. 
Assim, os poucos indicadores mostrados neste texto reatestam a importância de se proceder à investigação aprofundada sobre os mecanismos que operam a transferência do letramento escolar para o letramento social. Por serem os resultados muito incipientes, fica claro que as pesquisas na área ainda estão muito distantes do esperado em trabalho que se vem desenvolvendo no âmbito da EJA da UFRJ.

Muitas perguntas reafirmam-se ainda mais relevantes: (a) o conhecimento adquirido fora da escola, de forma assistemática, é suficiente para a inserção dos cidadãos na cultura letrada? (b) Se parte da resposta a (a) é verdadeira, que saberes são natural e espontaneamente adquiridos na vida? (c) Que conteúdos a escola deve incluir para complementar e promover a inclusão social plena do cidadão adulto? (d) Que modos se mostram mais eficazes para implementar o diálogo entre escola e vida?

\section{Referências bibliográficas}

MOLLICA, Maria Cecilia. Da linguagem coloquial à escrita padrão. Rio de Janeiro: 7 Letras, 2004.

; LEAL, Marisa. Português e Matemática: parceria indispensável em política educacional. In: SILVA, Camilo Rosa; HORA, Demerval da; CHRISTIANO, Maria Elizabeth A. (Org.). Lingüística e Práticas Pedagógicas. Pallotti, 2006a, p. 33-54.

Letramento \& Alfabetização: primeiro caderno. Rio de Janeiro: UFRJ, 2006b.

MOREIRA, Nadja da Costa Ribeiro. A concepção da escrita pela criança: portadores de texto - concepções de crianças quanto a atitudes, função e conteúdo. Campinas: Pontes, 1992.

SOARES, Magda. Letramento e escolarização. In: RIBEIRO, Vera Masagão (Org.). Letramento no Brasil: reflexões a partir do INAF 2001. São Paulo: Global, 2003.

\section{Autores}

\section{Maria Cecília de Magalhães Mollica}

Programa de Lingüística da Universidade Federal do Rio de Janeiro (CNPq/FAPERJ)

Telefone: (021) 2294-4883

Endereço Profissional: Universidade Federal do Rio de Janeiro, Faculdade de Letras, Departamento de Lingüística, Av. Brigadeiro Trompovsky, S/N - Ilha do Fundão - Rio de Janeiro - RJ - Brasil

Endereço Residencial: Rua Marquês de São Vicente, 512/403 - Gávea - Rio de Janeiro RJ - 22451-040 - Brasil

ceciliamollica@terra.com.br 


\section{Marisa Beatriz Bezerra Leal}

Instituto de Matemática da Universidade Federal do Rio de Janeiro

Telefone: (021) 2552-9834

Endereço Residencial: Rua Mundo Novo, 835 - Botafogo - 22251-020 - Rio de Janeiro RJ - Brasil

Endereço Profissional: Universidade Federal do Rio de Janeiro, Instituto de Matemática, Departamento de Métodos Matemáticos - Centro de Tecnologia (CT), Av. Brigadeiro Trompovsky, S/N - Ilha do Fundão - Rio de Janeiro - RJ - Brasil

marisaleal@im.ufrj.br

\section{Como citar este artigo:}

MOLLICA, Maria Cecília de Magalhães; LEAL, Marisa Beatriz Bezerra. Da escola para a vida: a importância do letramento escolar. Revista Moçambras: acolhendo a alfabetização nos países de língua portuguesa, São Paulo, ano 1, n. 2, 2007. Disponível em: <http://www.mocambras.org >. Publicado em: março 2007. 